\title{
First rib fracture and Horner's syndrome due to a motor vehicle collision: a case report
}

\author{
James Demetrious
}

\begin{abstract}
A case of a first rib fracture and Horner's syndrome due to a motor vehicle collision is reported. Initial evaluation in a hospital emergency department and follow-up by a medical primary care physician failed to provide identification of the Horner's syndrome. Careful assessment and review of the patient's symptoms, signs and images revealed this uncommon and important neurologic case presentation. A brief discussion related to traumatic first rib fracture, Horner's syndrome and arterial dissections of the neck is provided.
\end{abstract}

Keywords: Horner's syndrome, First rib, Fracture, Collision, Chiropractic, Dissection

\section{Background}

Making the diagnosis of Horner's syndrome requires careful consideration due to congenital, acquired, traumatic, compressive, invasive and iatrogenic etiologies [1-7]. The differential diagnosis of Horner's syndrome can be challenging due to possible disruption of sympathetic fibers of first, second or third order neurons $[4,5]$. Such lesions are variable in their presentation, scope and affect due to complex neuro-anatomic pathways and potential damage subject to the proximity of other anatomic structures.

The incidence of fracture of the first rib is uncommon and varied in its causation [8-10]. First rib fracture is rare possibly due to its protected anatomic location [11]. Such injuries are clinically important due to the proximity and potential compression of neighboring vascular and neurologic structures. In motor vehicle collisions, blunt trauma caused by sudden movement of the head that is abruptly stopped by a seatbelt or windshield may cause stress through scalene and sternocleidomastoid muscles producing bending strain through the first rib and resultant fracture [11].

This paper describes a case of a 72-year-old gentleman who experienced a first rib fracture and Horner's syndrome due to a motor vehicle collision.

Correspondence: dr.demetrious@gmail.com

Private Practice, Demetrious Chiropractic Orthopedics, 4837 Carolina Beach Road, Suite 205, Wilmington, NC 28412, USA

\section{Case presentation}

A 72-year-old man presented to our chiropractic office eight-weeks following a vehicular accident. While driving, he suffered a collision with an oncoming vehicle in which his car was impacted on its front left quarter panel. He wore a seatbelt and did not lose consciousness due to the impact.

The patient was transported via ambulance to a local hospital where evaluation and extensive imaging was immediately performed and read by different attending radiologists. The attending emergency medical physician diagnosed a rib fracture and the patient was subsequently released from the hospital. The patient sought care with his medical primary care physician and received a prescription for pain medication for the first rib fracture and neck pain. No other recommendations or care were provided to the patient.

The patient's wife reported that while visiting the patient at the hospital immediately following the car accident, she noted asymmetry and partial drooping of his right eyelid. No discussion of the drooping eyelid was made by the patient or his wife with the previous attending physicians.

The patient sought care in our chiropractic office eight weeks following the vehicular collision for assessment and care of persistent neck discomfort. His past history was negative for contributory medical, neurologic or ophthalmologic disorders. The patient's vital signs were normal. He was alert and oriented.
() Biomed Central

(c) 2013 Demetrious; licensee BioMed Central Ltd. This is an Open Access article distributed under the terms of the Creative Commons Attribution License (http://creativecommons.org/licenses/by/2.0), which permits unrestricted use, distribution, and reproduction in any medium, provided the original work is properly cited. 


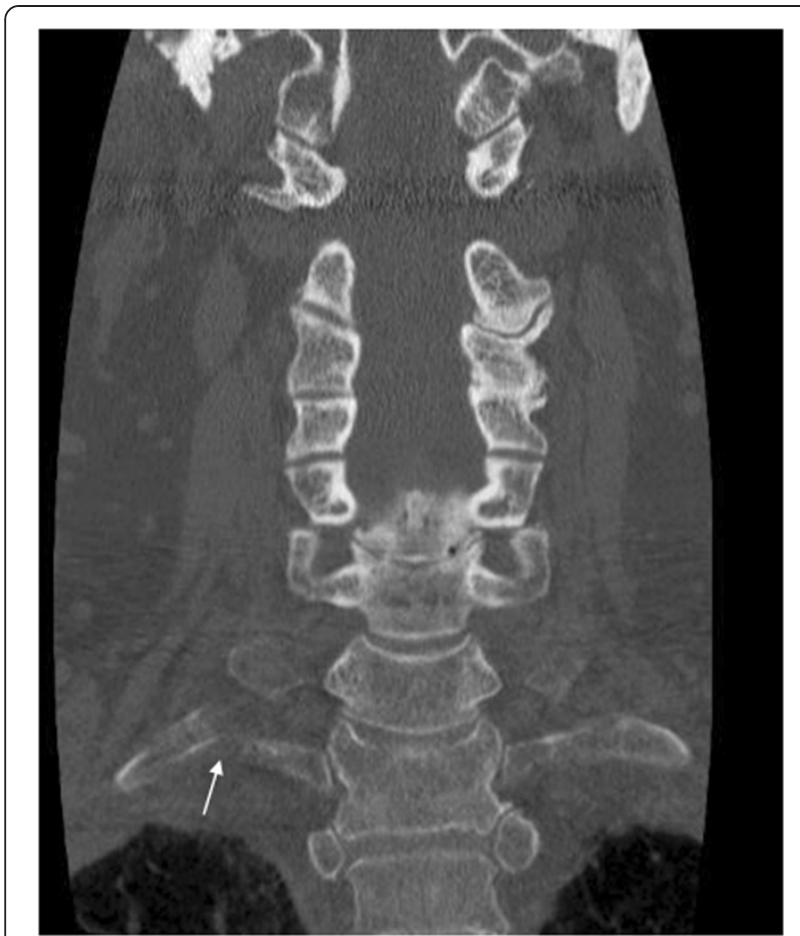

Figure 1 Non-contrast CT of the cervical spine. This coronal view reveals a displaced fracture of the proximal right first rib (white arrow).
Initial visual inspection revealed miosis and partial ptosis of the right eye. His right eye was not responsive to direct or consensual light. Cardinal fields of gaze were normal. The patient denied alteration of facial sensation or hemi-facial anhidrosis of the affected side. The remainder of the patient's cranial nerve examination was normal. Neurologic assessment of the extremities revealed normal sensory, deep tendon reflexes and motor function. Pathologic reflexes were not elicited. Cerebellar, coordination and balance evaluations were negative. Otoscopic examination was normal.

Auscultation of the carotid and subclavian arteries revealed no bruits. The lungs were clear to auscultation. Globally decreased cervical range of motion and localized tenderness was noted at $\mathrm{C} 7 / \mathrm{T} 1$. Palpation revealed tenderness of the first rib at the apex of the right lung. The patient reported localized discomfort at C7/T1 upon cervical compression, Spurling's test and Valsalva maneuver. No radiating pain was elicited. No other abnormalities were identified during physical examination.

\section{Imaging}

The following comprehensive imaging was performed upon initial evaluation at the hospital and read by different attending radiologists. All imaging reports and images performed following the vehicular collision were obtained from the hospital. A review of the radiology
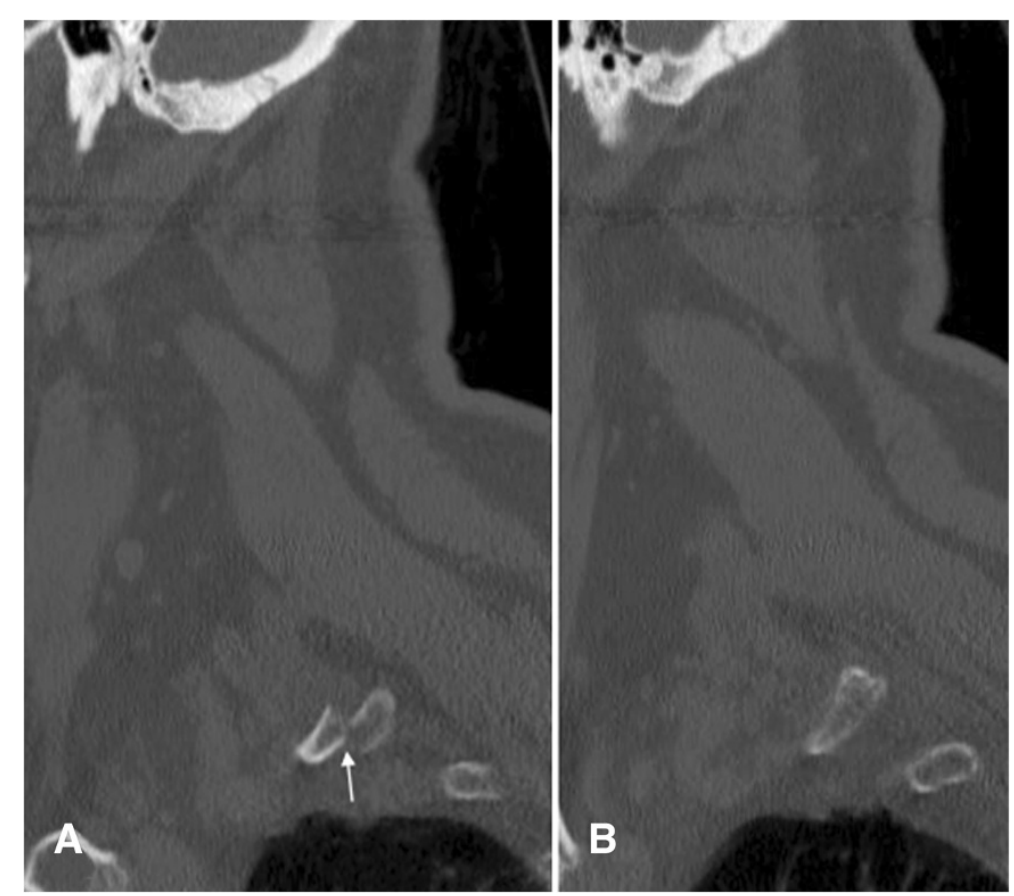

Figure 2 Non-contrast CT of the cervical spine. Sagittal image (A) reveals an anteriorly displaced fracture of the right first rib (white arrow). For comparison, image (B) reveals a normal left first rib. 

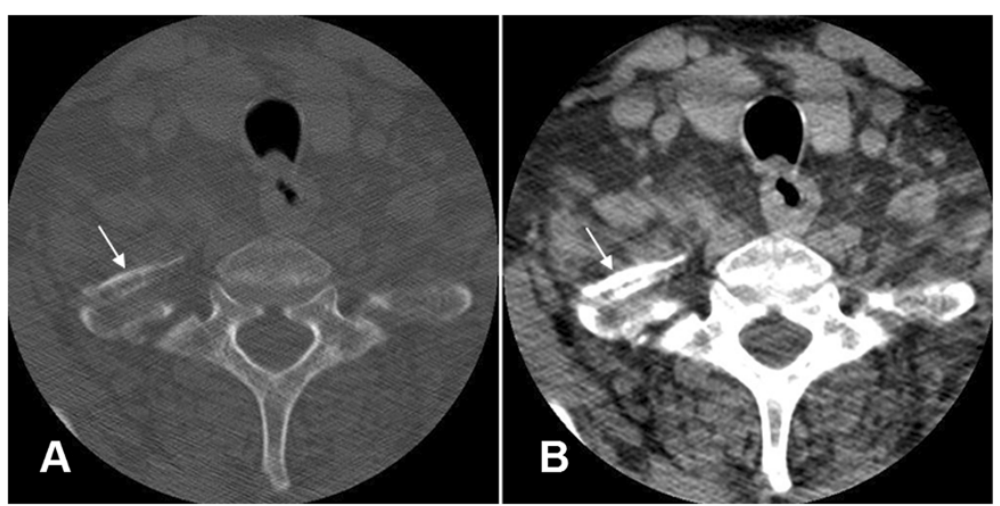

Figure 3 CT of the thoracic spine with contrast. The CT bone window image (A) and CT soft tissue window (B) reveal an anteriorly displaced rib fracture of the proximal right first rib (white arrows).

reports and careful over-read of all images was conducted in our office by the author:

- Computed tomography (CT) of the head without contrast revealed no acute findings.

- Non-contrast CT of the cervical spine with reformations revealed an acute, anteriorly displaced fracture of the proximal right first rib on coronal (Figure 1) and sagittal images (Figure 2).

- CT of the thoracic spine with contrast revealed an anteriorly displaced rib fracture of the proximal right first rib (Figure 3).

- An attending radiologist reported no acute abnormalities of the cervical spine magnetic resonance imaging (MRI) study. Subsequent overread in our office by the author revealed a displaced fracture at the proximal right first rib with increased signal intensity at the fracture site on $\mathrm{T} 2$ weighted images (Figure 4).

- CT of the chest with contrast was performed. The attending radiologist failed to report the first rib fracture. Subsequent over-read in our office by the author revealed an anteriorly displaced fracture fragment at the proximal right first rib on coronal (Figure 5) and axial images (Figure 6).

Horner's syndrome is present in up to $58 \%$ of internal carotid artery dissections [12]. Most patients experience neck, facial and head pain ipsilateral to the lesion because of ischemia or stretching of the trigeminal pain fibers surrounding the carotid arteries [13]. Ophthalmic manifestations have been reported to occur in up to $62 \%$ of patients with internal carotid artery dissection [13].

Due to the trauma sustained by the patient, persistent neck pain, the identified first rib fracture, persistent miosis and eyelid ptosis and concern for a traumatic arterial dissection, the patient was referred for a brain MRI and magnetic resonance angiography (MRA) examinations of the cervical and brain vessels $[5,12,13]$. He was also referred to a local neuro-ophthalmologist for assessment and follow-up.

The MRI and MRA studies were negative and the patient was provided a diagnosis of Horner's syndrome due to first rib fracture. No specific treatment was rendered. Over the period of one year, the patient recovered fully.
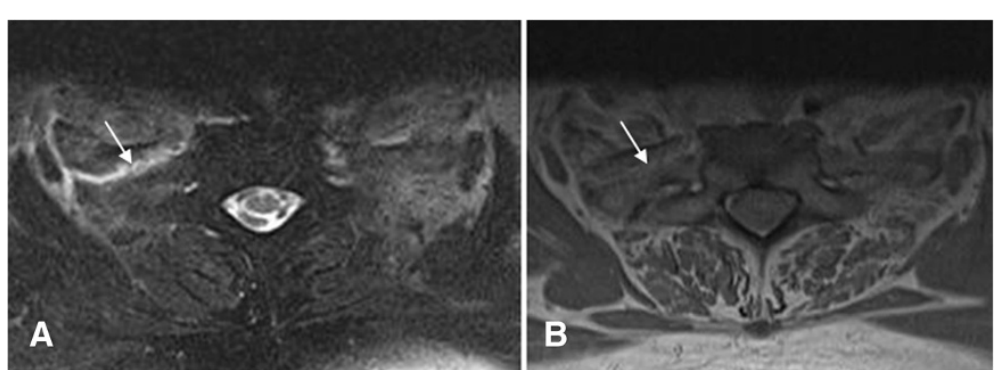

Figure 4 Cervical spine magnetic resonance imaging MRI. A T2 weighted image (A) reveals a displaced fracture at the proximal right first rib with increased signal intensity at the fracture site (white arrow). Image (B) reveals the displaced fracture at the proximal right first rib with isointense signal at the fracture site (white arrow). These findings are indicative of edema and hemorrhage. 


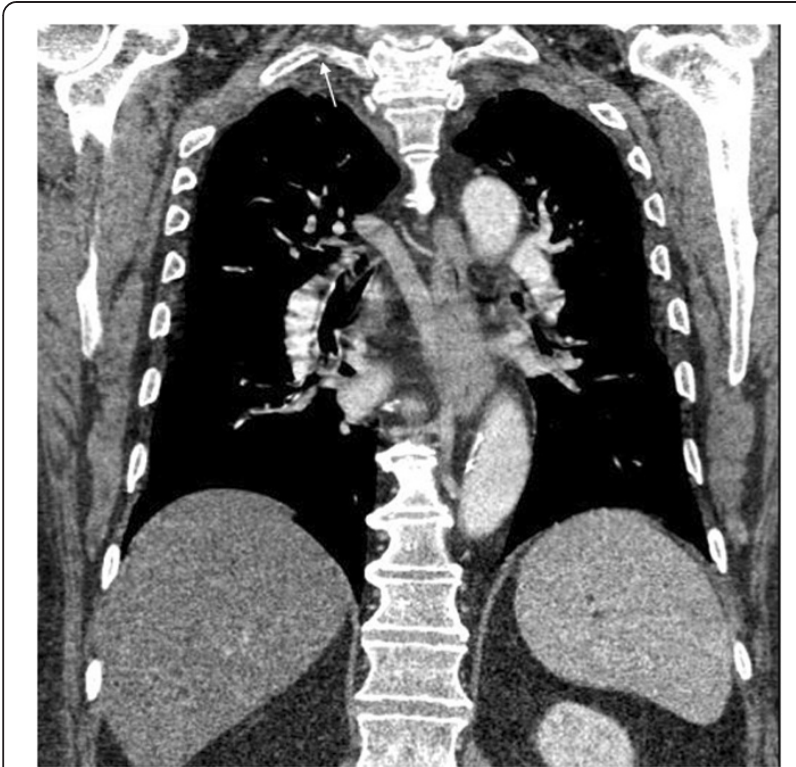

Figure $5 \mathrm{CT}$ of the chest with contrast. This coronal view reveals a displaced fracture fragment of the proximal right first rib (white arrow)

\section{Discussion}

The patient suffered Horner's syndrome due to a traumatic, second order neuronal lesion. Disruption and edema at the fracture site likely produced an oculo-sympathetic palsy due to compression of the neighboring stellate ganglion and sympathetic fibers [14].

All of the advanced imaging studies performed visualized the fractured first rib. However, attending radiologists failed to note the fracture in two imaging reports. It is important to recognize the fallibility and inherent difficulty of identifying rib fractures via imaging modalities. Cho et al. report that missed rib fractures are not uncommon [15].

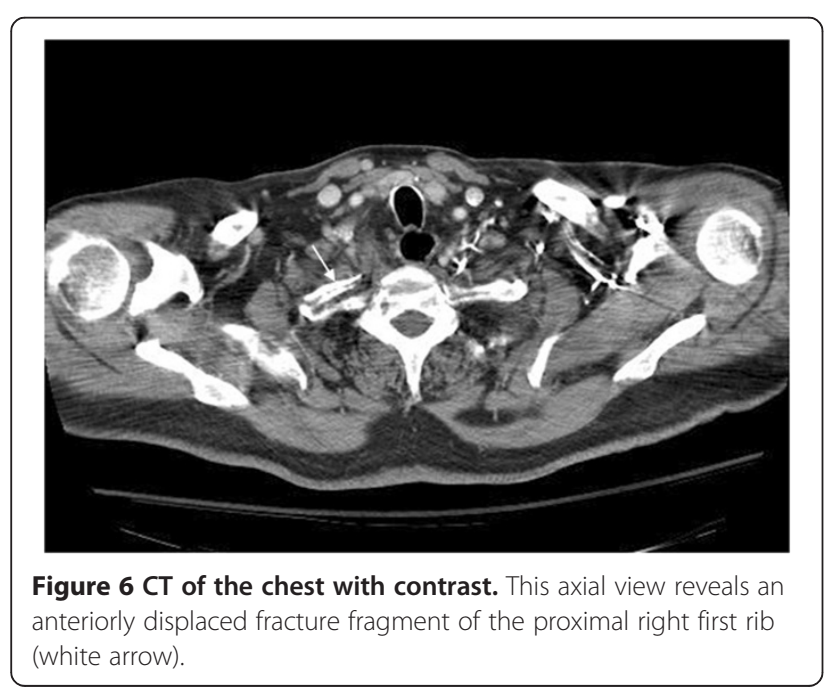

Despite the obvious visual cue of a drooping eyelid, the patient's attending medical providers did not properly assess this condition. This is critical as the patient could have suffered a traumatic arterial dissection that may have been undetected and untreated for that time period $[16,17]$. Such an error could have been catastrophic.

Had the patient suffered an undiagnosed post-traumatic arterial dissection, subsequent delivery of chiropractic adjustment, spinal manipulation or manual therapy could have been wrongly implicated as a causative etiology of the dissection and/or Horner's syndrome.

\section{Conclusions}

In this uncommon case, a first rib fracture caused by the trauma of a motor vehicle collision produced Horner's syndrome. While a ptotic eyelid might seem evident, it is possible as demonstrated in this case, to miss this important diagnosis. Horner's syndrome can be difficult to assess and bears due attentiveness and diagnostic consideration.

\section{Consent}

Written informed consent was obtained from the patient for publication of this case report and any accompanying images. A copy of the written consent is available for review by the Editor-in-Chief of this journal.

\section{Competing interests}

The author declares no competing interests.

\section{Author's information}

The author is a Fellow of the Academy of Chiropractic Orthopedists. He conducts a private practice in Wilmington, NC, USA and teaches postgraduate chiropractic coursework pertaining to advanced differential diagnosis.

Received: 25 March 2013 Accepted: 5 June 2013 Published: 5 July 2013

\section{References}

1. Davagnanam I, Fraser CL, Miszkiel K, Daniel CS, Plant GT: Adult Horner's syndrome: a combined clinical, pharmacological, and imaging algorithm. Eye 2013, 27:291-298.

2. Ahmadi O, Saxena P, Wilson BK, Bunton RW: First rib fracture and Horner's syndrome: a rare clinical entity. Ann Thorac Surg 2013, 95:355.

3. Yang CJ, Lee JY, Wu CC, Tsai JR, Chou SH, Huang MS: Right ptosis, anhidrosis, and miosis developed in a 49-year-old man with chronic dry cough for 2 months. Chest 2012, 142(1):246-251.

4. Mueller KL, Loder RT, Eggenberger ER, Farley FA: Horner's Syndrome after posterior spinal fusion in a child. Spine 2000, 25(21):2836-2837.

5. Mandal AKJ, Anandanadesan R, Missouris DG: The hazards of being a gentleman farmer: a case of transient Horner's syndrome. J $R$ Soc Med Sh Rep 2012, 3:53.

6. Lee SJ, Yie K, Chon SB: Juvenile first rib fracture caused by morning stretching. J Emerg Med 2012, 43(2):e119-e121.

7. Christine Whylings C, Kane BG: Adult female with shoulder pain. Ann Emerg Med 2011, 57:203.

8. Wild AT, Begly JP, Garzon-Muvdi J, Desai P, MCFarland EG: First-rib stress fracture in a high-school lacrosse player. Sports Health 2011, 3(6):547-549.

9. Sheng GG, Duwaryi YM, Emery VB, Wittenberg AM, Moriarty CT, Thompson RW: Costochondral calcification, osteophytic degeneration, and occult 
first rib fractures in patients with venous thoracic outlet syndrome. J Vasc Surg 2012, 55(5):1363-1369.

10. Melville JD, Lukefahr JL, Clarke EA: First rib fractures in abused infants: a report of three cases. Clin Pediatr 2012, 51(5):426-430.

11. Yee ES, Thomas AN, Goodman PC: Isolated first rib fracture: clinical significance after blunt chest trauma. Ann Thorac Surg 1981, 32:278-283,

12. Bougousslavsky J, Despland PA, Regli F: Spontaneous carotid dissection with acute stroke. Arch Neurol 1987, 44:479-482

13. Biousse V, Touboul PJ, D'Anglejan-Chatillon J, Levy C, Schaison M, Brousser MG: Ophthalmologic manifestations of internal carotid artery dissection. Am J Ophthalmol 1998, 126:565-577.

14. Slappendel R, Thijssen HOM, Crul BJP, Merz JL: The stellate ganglion in magnetic resonance imaging: a quantification of the anatomic variability. Anesthesiology 1995, 83(2):424-426.

15. Cho SH, Sung YM, Kim MS: Missed rib fractures on evaluation of initial chest CT for trauma patients: pattern analysis and diagnostic value of coronal multiplanar reconstruction images with multidetector row CT. Br J Radiol 2012, 85:e845-e850.

16. Chan CC, Paine M, O'Day J: Carotid dissection: a common cause of Horner's syndrome. Clin Experiment Ophthalmol 2001, 29(6):411-415.

17. Creavin ST, Rice CM, Pollentine A, Cowburn P: Carotid artery dissection presenting with isolated headache and Horner syndrome after minor head injury. Am J Emerg Med 2103, 30(9):e5-e7.

doi:10.1186/2045-709X-21-22

Cite this article as: Demetrious: First rib fracture and Horner's syndrome due to a motor vehicle collision: a case report. Chiropractic \& Manual Therapies 2013 21:22.

\section{Submit your next manuscript to BioMed Central and take full advantage of:}

- Convenient online submission

- Thorough peer review

- No space constraints or color figure charges

- Immediate publication on acceptance

- Inclusion in PubMed, CAS, Scopus and Google Scholar

- Research which is freely available for redistribution 